\title{
Real-time detection of TDP1 activity using a fluorophore-quencher coupled DNA-biosensor
}

\author{
Pia W. Jensen ${ }^{\mathrm{a}, \mathrm{b}}$, Mattia Falconi ${ }^{\mathrm{c}}$, Emil L. Kristoffersen ${ }^{\mathrm{b}}$, Anita T. Simonsen ${ }^{\mathrm{a}, \mathrm{b}}$, \\ Jèssica B. Cifuentes ${ }^{\mathrm{a}, \mathrm{b}}$, Lærke B. Marcussen ${ }^{\mathrm{b}}$, Rikke Frøhlich ${ }^{\mathrm{b}}$, Josephine Vagner ${ }^{\mathrm{a}}$, \\ Charlotte Harmsen $^{\text {b }}$, Sissel Juul ${ }^{\text {b }}$, Yi-Ping Ho ${ }^{\mathrm{d}}$, Marjorie A. Withers ${ }^{\text {e }}$, James R. Lupski ${ }^{\text {e,f,g }}$, \\ Jørn Koch ${ }^{\text {a }}$, Alessandro Desideri ${ }^{\text {c }}$, Birgitta R. Knudsen ${ }^{\text {b,d }}$, Magnus Stougaard ${ }^{\text {a,d,* }}$ \\ a Department of Pathology, Aarhus University Hospital, Denmark \\ ${ }^{\mathrm{b}}$ Department of Molecular Biology and Genetics, Aarhus University, Denmark \\ c Department of Biology, University of Rome "Tor Vergata", Via della Ricerca Scientifica, 00133, Interuniversity Consortium, National Institute Biostructure \\ and Biosystem (INBB), Italy \\ ${ }^{\mathrm{d}}$ Interdisciplinary Nanoscience Center (iNANO), Aarhus University, Denmark \\ e Department of Molecular and Human Genetics, Baylor College of Medicine, Houston, TX, USA \\ ${ }^{\mathrm{f}}$ Department of Pediatrics, Baylor College of Medicine, Houston, TX, USA \\ g Texas Children's Hospital, Houston, TX, USA
}

\section{A R T I C L E I N F O}

\section{Article history:}

Received 13 February 2013

Received in revised form

10 April 2013

Accepted 13 April 2013

Available online 25 April 2013

Keywords:

Tyrosyl-DNA phosphodiesterase 1 (TDP1)

Biosensor

Enzyme activity

Real-time measurement

Fluorophore-quencher

\begin{abstract}
A B S T R A C T
Real-time detection of enzyme activities may present the easiest and most reliable way of obtaining quantitative analyses in biological samples. We present a new DNA-biosensor capable of detecting the activity of the potential anticancer drug target tyrosyl-DNA phosphodiesterase 1 (TDP1) in a very simple, high throughput, and real-time format. The biosensor is specific for Tdp1 even in complex biological samples, such as human cell extracts, and may consequently find future use in fundamental studies as well as a cancer predictive tool allowing fast analyses of diagnostic cell samples such as biopsies. TDP1 removes covalent 3'DNA adducts in DNA single-strand break repair. This enzymatic activity forms the basis of the design of the TDP1-biosensor, which consists of a short hairpin-forming oligonucleotide having a 5'fluorophore and a 3'quencher brought in close proximity by the secondary structure of the biosensor. The specific action of TDP1 removes the quencher, thereby enabling optical detection of the fluorophore. Since the enzymatic action of TDP1 is the only "signal amplification" the increase in fluorescence may easily be followed in real-time and allows quantitative analyses of TDP1 activity in pure enzyme fractions as well as in crude cell extracts. In the present study we demonstrate the specificity of the biosensor, its ability to quantitatively detect up- or down-regulated TDP1 activity, and that it may be used for measuring and for analyzing the mechanism of TDP1 inhibition.
\end{abstract}

(c) 2013 Elsevier B.V. All rights reserved.

\section{Introduction}

Biosensors capable of detecting disease related enzymes and their drug response in complex biological samples have gained increasing interest during recent years; particularly due to the increase in highly specialized treatments targeting specific enzymes. Although most treatments are still based on an average patient response rate, the specific action of many clinically used drugs depend on specific enzymatic reactions, which may vary considerably between individuals (Belle and Singh, 2008). Hence,

\footnotetext{
*Correspondence to: Aarhus University Hospital, Department of Pathology, Noerrebrogade 44, building 18B, 8000 Aarhus C, Denmark. Tel.: +45 78463672.

E-mail address: magnstou@rm.dk (M. Stougaard).
}

besides the obvious interest to basic science there is a growing interest for biosensors capable of detecting the specific action of enzymes in complex biological samples such as crude cell extracts used for clinical applications. In line with this demand we have previously developed DNA-based biosensors capable of detecting the specific activity of human topoisomerase I (TopI), and the two related enzymes, Flp- and Cre recombinases, in crude cell extract (Andersen et al., 2009; Stougaard et al., 2009). These biosensors relied on rolling circle amplification (RCA) and allowed highly sensitive and quantitative detection of enzyme activities at the level of single catalytic events even in single cells (Juul et al., 2011). However, these assays were very time consuming and did not allow real-time measurement of the enzyme activities.

Although many different types of biosensors exist there are several advantages to use DNA-biosensors (Dai and Kool, 2011; 
Stougaard et al., 2011). One is that DNA is an easily manipulated nano-scale material and the sequence of the sensor may be designed to self-assemble into desired structures, which is especially useful in quencher-fluorophore setups. A second advantage is the ease of synthesis, and the many different modifications available such as different haptens, fluorophores, and quenchers. A third advantage is water solubility, which is high for DNAbiosensors due to the negatively charged phosphate backbone of DNA while often a challenge using classical small molecule sensors. Finally, when it comes to detecting the activity of DNA interacting enzyme activities e.g. DNA repair enzymes, DNAsensors present the obvious advantage of being a close-tonatural substrate for the enzyme activity.

An example of such a DNA repair enzyme is the important and cancer relevant enzyme tyrosyl DNA-phosphodiesterase 1 (TDP1). TDP1 was initially discovered by its ability to remove TopI covalently trapped to the 3'end of DNA by cleaving the 3'phosphotyrosyl linkage in TopI-DNA complexes, which are a natural intermediate of TopI catalysis (Yang et al., 1996). The human TDP1 gene was initially identified by genetic mapping and positional cloning in a family manifesting autosomal recessive spinocerebellar ataxia and axonal neuropathy (SCAN1) (Takashima et al., 2002) and its gene product TDP1 was shown to be instrumental to DNA single-strand break repair (SSBR) (El-Khamisy et al., 2005). TopI is an essential nuclear enzyme that regulates the topology of genomic DNA by introducing nicks in the DNA backbone using a mechanism that leads to a covalent bond between the enzyme and the generated 3'DNA end. Although these TopI-DNA complexes normally exist very transiently, endogenous DNA lesions (such as nicks, abasic sites, or mismatches) (Pourquier et al., 1997a, 1997b) or TopI poisons (such as the clinically used anti-cancer agents from the camptothecin (CPT) family) may prolong their half-life (Hsiang et al., 1985). If left unrepaired these TopI-DNA complexes will collide with transcription- or replication-forks resulting in DNA breaks and ultimately cell death or hyper-recombinogenic phenotypes. It appears to be this mechanism that explains the anticancer effect of CPTs. By removing TopI-DNA complexes TDP1 may play an important role in maintaining genomic stability and more specifically for preventing cancer development as well as for the expected outcome of cancer therapy using TopI directed drugs. Moreover, recent studies suggest the importance of TDP1 for the repair of a number of DNA lesions other than TopI-DNA complexes (Cheng et al., 2002; Das et al., 2010; Interthal et al., 2005a; Zhou et al., 2005).

TDP1 is up-regulated in non-small cell lung cancer (Liu et al., 2007) and in colon cancer (Yu et al., 2005), with relatively large variations between patients. Since overexpression of TDP1 in human cells has been shown to increase cellular resistance to CPTs (Barthelmes et al., 2004; Perego et al., 2012), CPT treatment of e.g. colon cancer in some patients might be counteracted by high TDP1 activity. A biosensor, capable of fast, sensitive, specific and quantitative detection of TDP1 activity on a cellular background in a high throughput assay, could thus prove useful for testing the TDP1 activity in individual patients and form the basis for individualized treatment.

Here, we present a new optical DNA-biosensor meeting these demands. The TDP1-biosensor enables real-time optical detection of TDP1 activity through the use of a quencher-flourophorer pair and it is specific even in complex biological materials such as crude cell extracts. Furthermore, the biosensor does not require any secondary amplification. The only reaction required for signal generation is mediated directly by TDP1 turnover of the biosensor molecule; hence the biosensor allows very precise detection of endogenous enzyme activity. With a design closely resembling the natural substrate for TDP1, the TDP1-biosensor would also be well suited for use in the screening of new inhibitors against TDP1.
We believe this to be an important attribute since there are still no specific TDP1 inhibitors approved for use in patients, although TDP1 has long been suggested as a future chemotherapeutic target (Beretta et al., 2010; Dexheimer et al., 2008; Hirano et al., 2007). Furthermore, due to the specificity of the TDP1-biosensor we envision it to be used both within academic research and in the future also for testing drug response in cellular systems and for analysis of clinical cell or tissue samples.

\section{Material and methods}

\subsection{Synthetic DNA oligonucleotides}

All DNA oligonucleotides were bought from DNA-Technology.

\subsection{Cloning and purification of recombinant wt-TDP1 and H493R- TDP1}

Total RNA from HeLa cells was purified using the Rneasy Mini Kit (Qiagen) and reverse transcribed into cDNA using the SuperScript II Reverse Transcriptase Kit (Invitrogen). TDP1 cDNA was obtained by gene specific PCR performed on the cDNA using the primers 5'-TCT CAG GAA GGC GAT TAT GGG-3' (forward) and 5'-TCA GGA GGG CAC CCA CAT-3' (reverse). The start codon was omitted, due to its presence in the cloning vector upstream of a His-tag. $200 \mathrm{nM}$ of each primer was used along with $\sim 50 \mathrm{ng}$ of HeLa cDNA in the Expand High Fidelity PCR System (Roche). Initial denaturation of the strands was performed for $10 \mathrm{~min}$ at $95^{\circ} \mathrm{C}$, and was followed by 30 cycles of, $45 \mathrm{~s}$ at $53{ }^{\circ} \mathrm{C}$ (annealing), $2 \mathrm{~min}$ at $72{ }^{\circ} \mathrm{C}$ (elongation) and $45 \mathrm{~s}$ at $95{ }^{\circ} \mathrm{C}$ (denaturation). The final elongation took place at $72{ }^{\circ} \mathrm{C}$ for $10 \mathrm{~min}$. After PCR amplification, 0.02 units/ $\mu \mathrm{L} \mathrm{Taq}$ polymerase (Invitrogen) was added directly to the reaction for $10 \mathrm{~min}$ at $72{ }^{\circ} \mathrm{C}$ to add A-overhangs for the subsequent cloning. The PCR product was purified from a $1 \%$ agarose gel using the Qiaquick Gel Extraction Kit (Qiagen) and cloned using the pTrcHis TOPO ${ }^{\circledR}$ TA Expression Kit (Invitrogen) according to the manufacturer's protocol. The H493R-hTDP1 was generated using the QuikChange II Site-Directed Mutagenesis kit (Stratagene) with the primers 5'-CCA TGC CAC GTA TTA AGA C-3' (forward) and 5'-GTC TTA ATA CGT GGC ATG G-3' (reverse) according to the manufacturer's protocol.

Purified constructs of wt-hTDP1 and H493R-hTDP1 were obtained using the Plasmid Mini Kit (Qiagen) and confirmed by sequencing using the primers encompassing the beginning and end of the gene 5'-TCT CAG GAA GGC GAT TAT GGG-3' (forward) and 5'-TCA GGA GGG CAC CCA CAT-3' (reverse) along with additional primers located within the sequence: 5'-GCA GAA GCA GGC TGA GAA AGT G-3' (bases 602-623), 5'-GCG AGA GGC TAA GGC TCA CCT-3' (bases 992-1012), and 5'-CCA GGA CGC TTT CAA GGA AGT C-3' (bases 1374-1395). The TDP1 constructs was transformed into BL21 competent cells (wt-hTDP1) or XLBlue competent cells (H493R-hTDP1) and the constructs were confirmed by Sanger sequencing. Subsequently the TDP1 enzymes were expressed and purified essentially as described by Interthal et al., (2001).

\subsection{Radioactive labeling and TDP1 cleavage of quencher substrates}

For the gel-based assay $20 \mathrm{nt}$ oligonucleotides (5'-ATA CGG TCT CGC AGA TCG CT-3') containing different 3'moities, namely phosphate (the length control), biotin, or either of the quenchers Dabsyl, BHQ1, BHQ3, and BBQ650 were linked through a phosphodiester bond. Two oligonucleotides with biotin were used, one linked through a phosphodiester bond (positive control) and the other linked through a phosphothioate linkage (negative control). 
All oligonucleotides were gel-purified (eluted in $500 \mathrm{mM}$ ammonium acetate $\mathrm{pH} 8,10 \mathrm{mM}$ magnesium acetate, $0.1 \mathrm{mM}$ EDTA, and $0.1 \%$ SDS, and EtOH precipitated) and radioactively labeled with $\gamma$ ATP using T4 Polynucleotide Kinase according to the manufacturer's protocol (Invitrogen). The oligonucleotides were EtOH precipitated and redissolved in $20 \mathrm{mM}$ Tris- $\mathrm{HCl}$ (pH 8), $100 \mathrm{mM}$ $\mathrm{KCl}, 10 \mathrm{mM}$ EDTA, and $1 \mathrm{mM}$ DTT. One thousand counts of each substrate were reacted with $2.5 \mathrm{ng}$ TDP1 or H493R-hTDP1 in a buffer containing $20 \mathrm{mM}$ Tris- $\mathrm{HCl}(\mathrm{pH} 8), 100 \mathrm{mM} \mathrm{KCl}, 10 \mathrm{mM}$ EDTA, and $1 \mathrm{mM}$ DTT for 20 min (wt-TDP1) or overnight (H493RTDP1) before heat inactivation at $95{ }^{\circ} \mathrm{C}$ for $5 \mathrm{~min}$ followed by addition of $1 \times$ volume formamide loading buffer (95\% formamide, $0.025 \%$ SDS, $0.025 \%$ bromophenol blue, $0.025 \%$ xylene cyanol $\mathrm{FF}$, and $0.5 \mathrm{mM}$ EDTA). The products were run on a $14 \%$ denaturing sequencing gel and stained with ethidium bromide.

The gel images were analyzed in QuantityOne (Bio-Rad) and the ratio of cleaved substrate was calculated at all the enzyme concentrations. For normalization, the ratio of cleaved substrate in the negative sample was subtracted and new averages and standard deviations were calculated.

\subsection{Cell culture, transfection, and preparation of nuclear extract}

Lymphoblastoid cells derived from a SCAN1 patient homozygous for the TDP1 mutation H493R, or a normal individual were grown in suspension in RPMI 1640 media, 15\% FBS, and 1\% PenStrep. HeLa and HEK293T cells were grown as adherent cells in DMEM+GlutaMAX, 10\% FBS, and 1\% PenStrep. Cells were split and/or harvested using $0.05 \%$ Trypsin-EDTA. All reagents were from GIBCO.

Nuclear extracts were made by lysing the cells in $1 \mathrm{~mL}$ of lysis buffer (0.1\% Igepal, $10 \mathrm{mM}$ Tris, $\mathrm{pH} 7.9,10 \mathrm{mM} \mathrm{MgCl}, 15 \mathrm{mM} \mathrm{NaCl}$, $0.1 \mathrm{mM}$ phenylmethyl sulfonyl fluoride, and $1 \mathrm{mM}$ dithiothreitol) for $10 \mathrm{~min}$ on ice. The released nuclei were sedimented for $4 \mathrm{~min}$ at $2000 \mathrm{rpm}$ and the supernatant was removed. Nuclear extraction buffer (20 mM HEPES, pH 7.9, 20\% glycerol, $0.4 \mathrm{M} \mathrm{KCl}$, and protease inhibitors) at $3 \times$ the volume of the pellet was added for a final concentration of $300 \mathrm{mM} \mathrm{KCl}$, to extract the nuclear proteins. After incubation for $1 \mathrm{~h}$ with gentle shaking the samples were spun for $10 \mathrm{~min}$ at $11,000 \mathrm{rpm}$ and the nuclear extracts were transferred to new tubes.

Transient transfection of HEK293T cells with the expression plasmid, pcDNA3.1/V5-His-TOPO with the gene sequence of TDP1 inserted according to manufacturer's instructions, was performed using lipofectamine2000 (Invitrogen) according to the manufacturer's instructions. Transfection efficiencies as measured by the expression of a green fluorescent protein (GFP) control construct were $>80 \%$. Mock-transfected cells were treated identically except that the plasmid was exchanged for $\mathrm{ddH}_{2} \mathrm{O}$. Forty-eight hours after transfection, the cells were harvested for preparation of nuclear extracts as described previously.

Knockdown of TDP1 in HEK293T cells was performed using a cocktail of three different TDP1-siRNAs (cat.no. sc41056 Santa Cruz Biotechnology). Transfection was performed according to the calcium phosphate transfection method (Graham and van der Eb, 1973; Wigler et al., 1978) followed by glycerol shock (Grosjean et al., 2006). Mock-transfected cells were treated identically except that the siRNA was exchanged for $\mathrm{ddH}_{2} \mathrm{O}$. Twenty-four hours after transfection, cell cultures were harvested for preparation of nuclear extracts as described previously.

\subsection{Western blot}

$15 \mu \mathrm{L}$ of each of the nuclear extracts were run on a $10 \%$ SDS gel. The proteins were transferred to a Protran nitrocellulose membrane at $100 \mathrm{~V}$ for $1 \mathrm{~h}$ using a CAPS transfer buffer (10 mM CAPS,
$\mathrm{pH} 10.5$, and $10 \% \mathrm{EtOH})$. The membrane was blocked for $1 \mathrm{~h}$ in $1 \times$ TBST (20 mM Tris pH 7.5, $0.5 \mathrm{M} \mathrm{NaCl}$ and $0.23 \%$ Tween-20) with $5 \%$ milk powder (making up the blocking buffer) and subsequently incubated over night at $4{ }^{\circ} \mathrm{C}$ with $5 \mathrm{~mL}$ blocking buffer containing $5 \mu \mathrm{L}$ Rabbit primary-antibody to TDP1 (abcam) or $1 \mu \mathrm{L}$ Mouse mantibody to Tata Binding Protein (TBP-used as a loading control) (abcam). The membrane was washed $3 \times 30 \mathrm{~min}$ in TBST before incubation with $1 \mu \mathrm{L}$ of the secondary HRP labeled antibody (Goat Anti-Rabbit Immunoglobulins/HRP or Polyclonal Goat Anti-Mouse Immunoglobulins/HRP) in $5 \mathrm{~mL}$ blocking buffer for $40 \mathrm{~min}$ at room temperature. Finally the membrane was washed $3 \times 15$ min with $1 \times$ TBST before development using the ECL Plus Western Blotting Detection System (GE Healthcare).

\subsection{Real-time detection of TDP1 activity}

The TDP1 activity measurements were carried out using a final concentration of $1 \mu \mathrm{M}$ TDP1-biosensor (6FAM-AAA GCA GGC TTC AAC GCA ACT GTG AAG ATC GCT TGG GTG CGT TGA AGC CTG CTT T-BHQ1, where the 6FAM was attached to the DNA through a phosphothioate- and the 3'BHQ1 through a phosphodiester linkage) in a volume of $25 \mu \mathrm{L}$ containing $1 \times$ TDP1 buffer ( $20 \mathrm{mM}$ Tris$\mathrm{HCl} \mathrm{pH} 8,100 \mathrm{mM} \mathrm{KCl}, 10 \mathrm{mM}$ EDTA, $10 \mathrm{mM}$ DTT, and 0.05\% Triton $\mathrm{X}-100$ ) supplemented with a dilution series of $6.25-12.5 \mathrm{pg}$ of purified wt- or H493R-TDP1. The reactions were incubated at a constant temperature of $37^{\circ} \mathrm{C}$ in a Bio-Rad iCycler IQ real-time PCR machine set to measure fluorescence every $1 \mathrm{~min}$. The data were imported into excel and the slope during the linear phase (here data from 15-30 min) was calculated for each of the different dilutions of TDP1.

Measurements of TDP1 activity in cell extract were performed as described above except that instead of using purified enzyme $2.5 \mu \mathrm{L}$ cell extract was used per $25 \mu \mathrm{L}$ reaction (the equivalent of 285,000 cells per reaction). Inhibition of TDP1 activity was performed as above using $6.25 \mathrm{ng}$ wtTDP1, except that the reaction was supplemented either with water or increasing amounts of vanadate ( $1 \mathrm{mM}, 5 \mathrm{mM}$, or $10 \mathrm{mM}$ final concentrations).

For the kinetic analysis of vanadate inhibition, $4.17 \mathrm{ng}$ wtTDP1 along with a biosensor dilution series $(5-0.1 \mu \mathrm{M})$ and a final concentrations of $0 \mathrm{mM}, 1.5 \mathrm{mM}$, or $3 \mathrm{mM}$ vanadate was used in $25 \mu \mathrm{L} 1 \times \mathrm{TDP} 1$ buffer and the reaction was incubated at $37{ }^{\circ} \mathrm{C}$ in a real-time PCR machine measuring fluorescence output every $15 \mathrm{~s}$ or $30 \mathrm{~s}$. The transformation from fluorescence to concentration of product was achieved by making a standard-curve from the current data set at late time points where the fluorescence had reached maximum.

After the transformation from fluorescence to concentration of product, slopes from a linear fit of the first $150 \mathrm{~s}$ were calculated for all samples and the slope values were plotted directly. Data were managed in Excel (Microsoft) and plots were fitted to a Michaelis-Menten model using GraphPad Prism (GrapgPad software Inc.). Data achieved under experiment conditions fulfilled the standard Michaelis-Menten assumptions: (1) $[S] \gg[E]$, (2) $\Delta G \ll 0$ and (3) $\left[E_{\mathrm{t}}\right]=\left[E_{0}\right]$.

\section{Results and discussion}

\subsection{Expression and purification of TDP1 enzyme}

To enable development and optimization of a biosensor for the specific detection of TDP1 in a controlled setup using pure recombinant enzyme, the gene encoding wt-TDP1 was cloned from human cDNA. Moreover, an activity reduced TDP1 variant, H493R-TDP1, with the active site histidine 493 mutated to an arginine was generated using quikchange site-directed 
mutagenesis. Both constructs were expressed in E. coli and the enzymes purified to close to homogeneity (data not shown). These purified enzyme fractions were subsequently used for testing the biosensor design as described below.

\subsection{Investigation of the ability of $3^{\top} \mathrm{DNA}$ coupled quenchers to function as substrate for TDP1}

The design of the biosensor for real-time measurement of TDP1 activity was based on the ability of TDP1 to remove different $3^{\prime}$ lesions from DNA, lesions which could potentially be incorporated in a hairpin structure containing a quencher-fluorophore pair. The idea relies on a design where removal of a quencher by TDP1 may be optically detected and measured through the resulting increase in fluorescent emission over time.

The natural substrates for TDP1 are the phosphotyrosyl bond linking TopI to the 3'end of DNA or a phosphodiester bond of the DNA backbone. TDP1 has also been shown to cleave a broad range of other chemical moieties of the 3'end of DNA with varying efficiency (Dexheimer et al., 2010; Inamdar et al., 2002; Interthal et al., 2005a). However, removal of quenchers has never been demonstrated. For the development of an optical TDP1-specific DNA-based biosensor it was therefore first necessary to investigate the ability of TDP1 to remove 3'DNA coupled quencher moieties.

For validation of a new biosensor in crude biological samples it is crucial to have suitable negative control samples without the selected target of the biosensor. A point mutation causing a H493R missense mutation in TDP1 observed in the autosomal recessive disease spinocerebellar ataxia with axonal neuropathy (SCAN1) (Takashima et al., 2002) that alters DNA SSBR (El-Khamisy et al., 2005) has been shown to reduce the activity of TDP1 on $3^{\prime}$ phosphotyrosyls (Interthal et al., 2005b) and to cause a total loss of function on 3'phosphoglycolates (Hawkins et al., 2009; Zhou et al., 2005). Therefore, we hypothesized that a quencher recognized as a substrate by wild type TDP1 (wt-TDP1), but not by H493R-TDP1 in cellular extracts from a SCAN1 homozygote mutant cell line (Takashima et al., 2002), would enable validation of the biosensor.

Based on these considerations we first created a series of inexpensive linear DNA substrates to investigate which 3'-DNA coupled quenchers could function as substrates for wt-TDP1 and not for H493R-TDP1. Four different DNA-quencher substrates having Dabsyl (Dab), Black Hole Quencher 1 or 3 (BHQ1 and BHQ3, respectively), or the Black Berry Quencher (BBQ) coupled to the DNA 3'end through a phosphodiester linkage (Fig. 1A) were tested in a standard gel-based assay as substrates for wt-TDP1 and H493R-TDP1, respectively. As positive control we used a DNAsubstrate with a phosphodiester linked biotin (Bio) since such a substrate previously has been shown to be recognized by TDP1 (Interthal et al., 2005a), and as negative control we used a DNAsubstrate with a phosphothioate linked biotin (ptBio) (Fig. 1A) since TDP1 is incapable of cleaving phosphothioate linkages (Dexheimer et al., 2010).

As illustrated in Fig. 1B, wt-TDP1 was able to cleave all four quenchers tested, although an approximately two fold difference between the most efficient (BBQ and BHQ1) and least efficient (BHQ3) DNA-quencher substrate for wt-TDP1 was observed. In contrast the H493R-TDP1 mutant enzyme exhibited weak or no cleavage activity of the four quenchers with BHQ1 being the least and $\mathrm{BBQ}$ being the most efficient substrate for the mutant enzyme (Fig. 1B). As expected the phosphodiester linked biotin substrate was cleaved both by wt-TDP1 and H493R-TDP1 whereas the phosphothioate linked biotin substrate was not (Fig. 1B).

Based on this we concluded that although the BBQ650 quencher seemed to result in the highest amount of cleavage with wt-TDP1 it was not optimal for our purposes as it also supported some cleavage of the H493R-TDP1. By contrast, the second best substrate for wt-TDP1, BHQ1, did not support H493R-TDP1 mediated cleavage and it gave the highest ratio between the fraction cleaved by the wt-TDP1 and the fraction cleaved by H493R-TDP1 (Fig. 1C). Thus, due to its high reactivity with wtTDP1 combined with a loss of function as a substrate for H493RTDP1, we concluded that the BHQ1 quencher was the best candidate to use in a TDP1-specific hairpin-style biosensor to be validated in a homozygote SCAN1 cell line.

\subsection{Design and testing of the real-time TDP1-biosensor}

TDP1 is capable of removing 3 'lesions from both single- and double-stranded DNA fragments with a slight preference for double-stranded blunt ends over single-stranded 3'ends (Raymond et al., 2005). Therefore, we decided to aim for a double-stranded biosensor design presenting a $3^{\prime}$ quencher and $5^{\prime}$ fluorophore pair at a blunt end. To minimize the risk of false positives due to removal of the fluorophore, this moiety was attached to the DNA through a phosphothioate linkage. The DNA sequence was designed with internal complementary sequences connected by a loop (Fig. 2A). This enables the DNA backbone of the TDP1-biosensor to fold into a stem-loop structure bringing the $3^{\prime}-$ and 5 'end into proximity resulting in quenching of the fluorophore. Upon reaction of the biosensor with TDP1 the quencher is expected to be removed from the 3 'end resulting in a quantitative fluorescence emission (Fig. 2A). In the initial tests of the biosensor reported here, an increase in fluorescence was measured using a regular real-time PCR machine standard in most biological or clinical laboratories. In principle, since the reaction is isothermal any instrument capable of measuring fluorescence over time could be used.

To investigate whether the TDP1-biosensor could be used for quantitative detection of TDP1 activity, the biosensor was incubated with serial dilutions of recombinant wt-TDP1 or H493RTDP1 and the increase in fluorescence was measured over time (Fig. 2B). To ensure precise activity measurements and to avoid substrate depletion influencing our calculations, only the slope in the initial linear phase of the reaction was used as measure for the level of activity. As seen in Fig. 2B and 2C, the detection limit corresponded to approximately 7 pM TDP1. This detection limit is slightly better or similar to (depending on the reaction conditions) the approximate detection limit of standard gel-electrophoretic assays based on radiolabeled DNA substrates. Compared to two previously published TDP1-biosensors the TDP1-biosensor presented here seems more sensitive than the p-nitrophenyl-tymidine-3'-phosphate TDP1-biosensor presented by Cheng et al., (2002), and comparably sensitive to the MUP-based (3'(4methyl-umbelliferone)-phosphate) TDP1-biosensor presented by Rideout et al., (2004).

As expected from the gel-based assay, H493R-TDP1 did not react with our TDP1-biosensor even at the highest enzyme concentration (3.4 nM) employed (Fig. 2B). In fact a small decrease in fluorescence, even after subtracting the fluorophore-bleaching calculated from the slope of no-enzyme sample, was observed upon incubation with H439R-TDP1, which could result from H493R-TDP1 further quenching the fluorophore upon binding to the biosensor.

The presented TDP1-biosensor consists of a DNA backbone with a 3'lesion (BHQ1), and it is thus very similar to the natural substrates for TDP1. This similarity may be important for screening of TDP1 inhibitors both because TDP1 has been suggested to act using a scanning mechanism, binding DNA non-specifically upstream of a blocking 3'moiety and subsequently scanning toward the 3'end (Dexheimer et al., 2010), and as a consequence of DNA binding/intercalation contributing to the potency of TDP1 
A

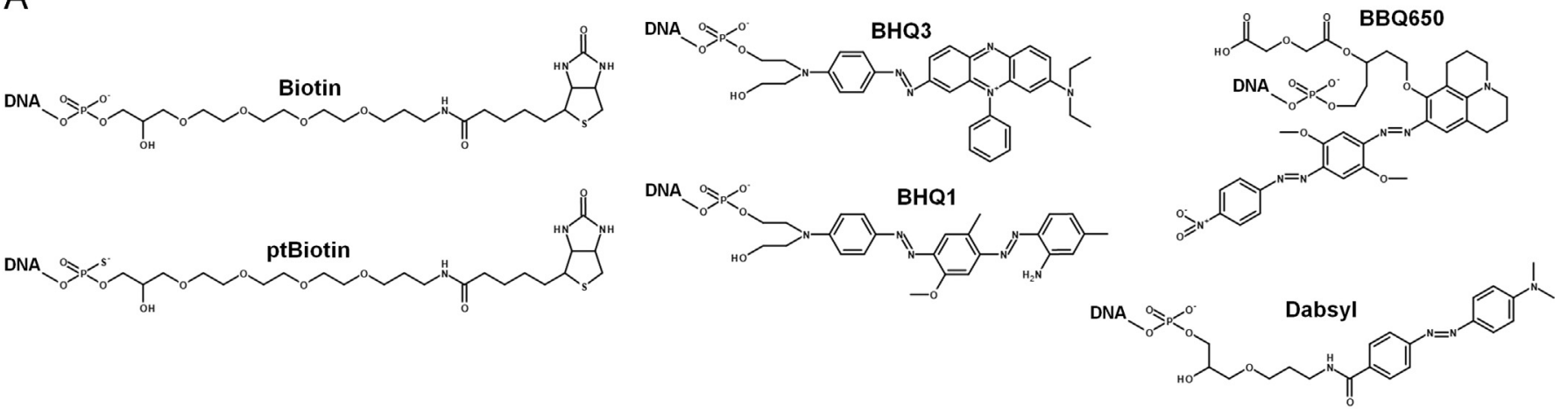
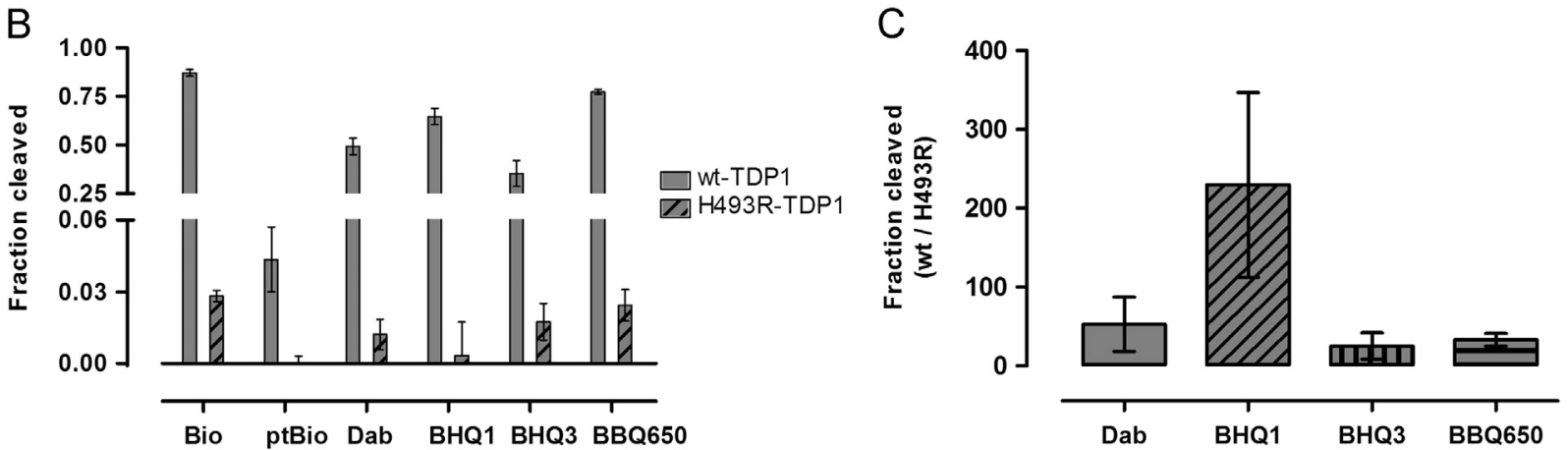

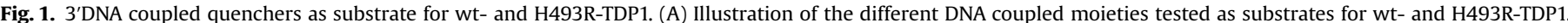

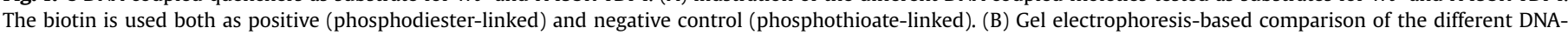

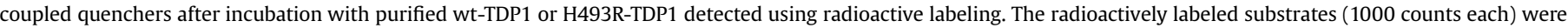

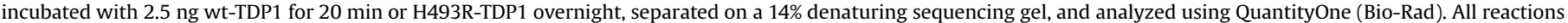

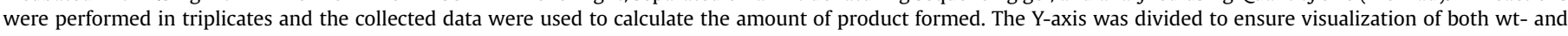

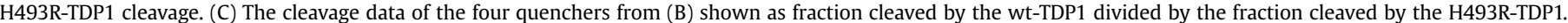

inhibitors such as it has been suggested for the TDP1 inhibitor furamidine (Antony et al., 2007). Consequently, we tested whether the TDP1-biosensor could measure inhibition of TDP1 by incubating the biosensor with purified TDP1 in the presence of different concentrations of vanadate. Vanadate is a general inhibitor of phosphatases and phosphotyrosine phosphatases and has been shown to inhibit TDP1 activity in mM concentrations (Davies et al., 2002). As seen in Fig. 3A a clear decrease in TDP1 activity was observed upon addition of increasing vanadate concentration to the reaction mixture. This result suggests that the TDP1-biosensor may be used for measuring inhibition of TDP1 and thereby provide a valuable tool for high throughput drug screening setups.

Furthermore, we examined the TDP1 reaction kinetics in the presence of vanadate. Vanadate is known to be a competitive inhibitor binding in the active site of enzymes and thereby competing with the substrate for enzyme interaction. We would therefore expect vanadate mediated inhibition of TDP1 measured with the TDP1-biosensor to follow the Michaelis-Menten kinetics for a competitive inhibition, where the $V_{\max }$ is identical for reactions with or without inhibitor and the apparent $K_{\mathrm{M}}\left(K_{\mathrm{M}}{ }^{\text {app }}\right)$ values are increasing proportional to the inhibitor concentration. To address this issue the TDP1-biosensor was incubated with a fixed final concentration of purified wt-TDP1 (2.4 nM) and $0 \mathrm{mM}$, $1.5 \mathrm{mM}$, or $3 \mathrm{mM}$ vanadate. The results are shown in Fig. $3 \mathrm{~B}$ and demonstrate that the $V_{\max }$ is approximately the same at $0 \mathrm{mM}$, $1.5 \mathrm{mM}$ and $3 \mathrm{mM}$ vanadate $\left(47 \times 10^{-5}\left( \pm 1 \times 10^{-5}\right) \mu \mathrm{M} / \mathrm{s}\right.$, $48 \times 10^{-5}\left( \pm 3 \times 10^{-5}\right) \mu \mathrm{M} / \mathrm{s}$, and $47 \times 10^{-5} \quad\left( \pm 4 \times 10^{-5}\right) \mu \mathrm{M} / \mathrm{s}$, respectively), whereas the $K_{\mathrm{M}}$ app values increase proportional to the concentration of inhibitor corresponding to a $K_{\mathrm{M}}$ of 0.36 $( \pm 0.035) \mu \mathrm{M}$ for the reaction without vanadate and a $K_{\mathrm{I}}$ of 439.085 ( \pm 28.97$) \mu \mathrm{M}$ calculated from the data with $1.5 \mathrm{mM}$ and
$3 \mathrm{mM}$ vanadate, having a $K_{\mathrm{M}}^{\text {app }}$ of $1.64 \mu \mathrm{M}$, and $2.71 \mu \mathrm{M}$, respectively. From our data with no vanadate the $k_{\text {cat }}$ was calculated $\left(11.66 \mathrm{~min}^{-1}\right)$. Other studies of human TDP1 kinetics (Cheng et al. 2002) find a $k_{\text {cat }}$ value within the same region $\left(8.82 \mathrm{~min}^{-1}\right)$, but a $K_{\mathrm{M}}$ that differs by several orders of magnitude $(211.14 \mu \mathrm{M})$. Since TDP1 binds double stranded DNA in vivo the $K_{\mathrm{M}}$, which indicates the strength of the enzyme-substrate binding, is expected to be higher for the small molecule substrate used in Cheng et al. corresponding to a less tight binding of the small molecule substrate compared to a double stranded DNA substrate. The $k_{\text {cat }}$ value is however expected to be comparable for both substrates because the enzymatic cleavage reaction, performed by TDP1, is equivalent for both substrates. Thus, our data confirm that vanadate is a competitive inhibitor of TDP1 and further suggests that the TDP1-biosensor may be used as an easy and rapid way to examine both the strength and the mechanism of drug inhibition. It may therefore become useful in future screening and analysis of TDP1 inhibitors.

\subsection{Validation of the TDP1-biosensor in human cells}

The previously published TDP1-biosensors (Cheng et al., 2002; Rideout et al., 2004) were not tested for specificity on a cellular background and may, hence, be limited to in vitro analyses of purified TDP1. To investigate if the TDP1-biosensor presented here is capable of specific detection of TDP1 activity in complex biological material such as extracts from human cells containing numerous other DNA repair enzymes, nucleases and other enzymatic activities, the TDP1-biosensor was reacted with various cell extracts in a divalent cation-depleted buffer. This was done to minimize interference from endogenous DNA modifying enzymes, 
A

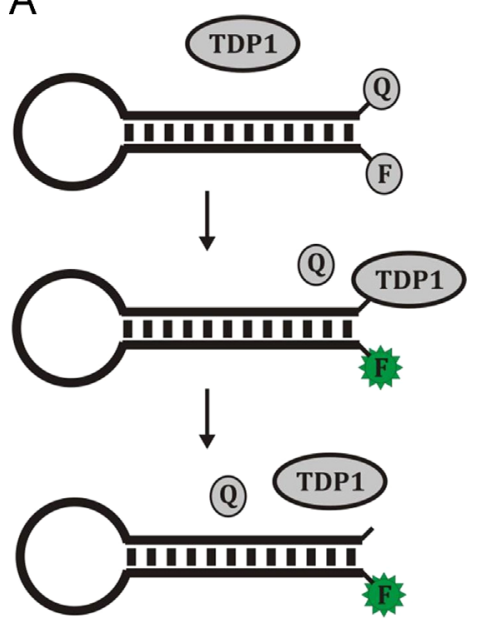

$\mathrm{B}$

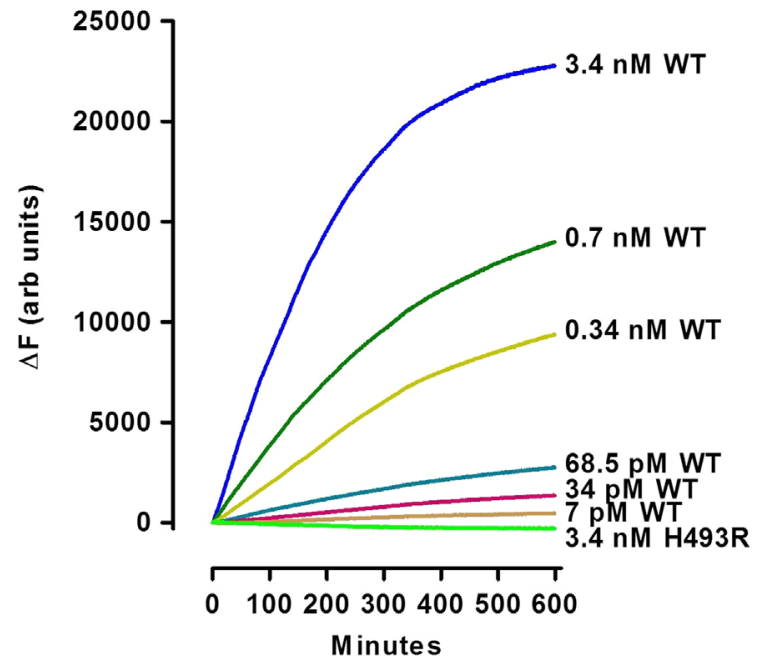

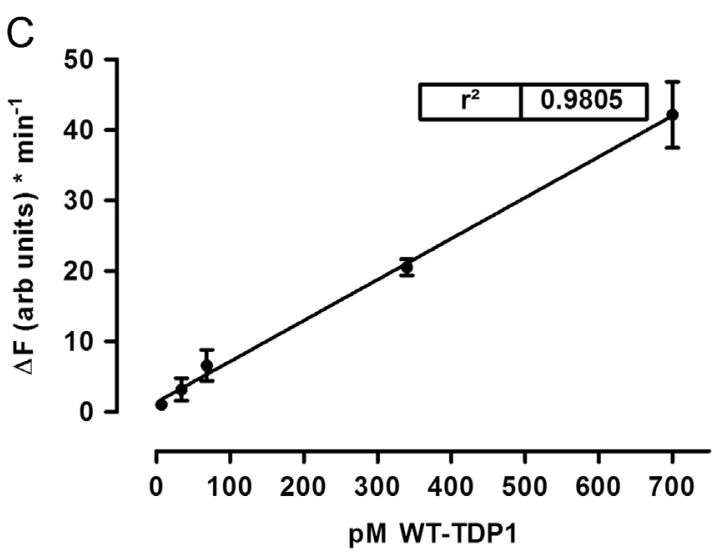

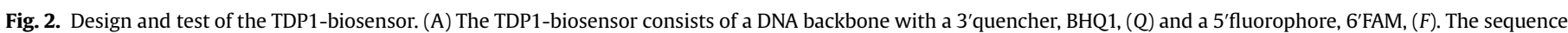

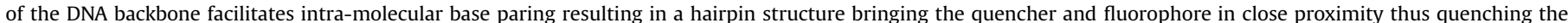

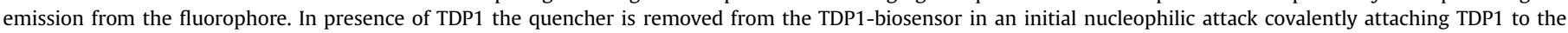

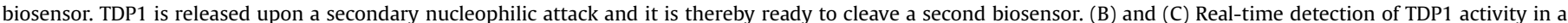

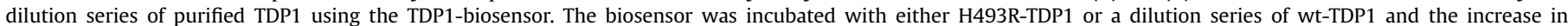

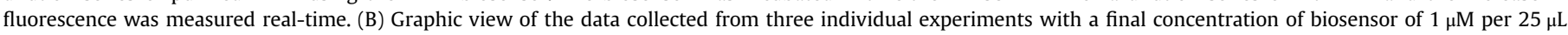

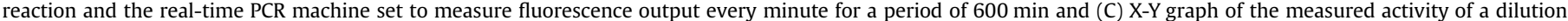

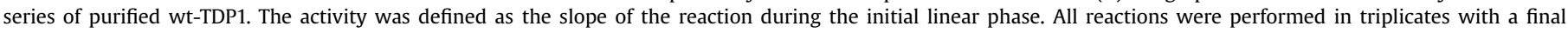

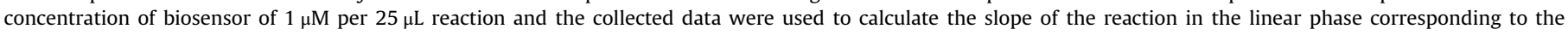
enzymatic activity of TDP1.

most of which require $\mathrm{Mg}^{2+}$ for activity. First the specificity of the TDP1-biosensor was tested using extract from an EBVimmortalized lymphoblastoid cell line (LCL) derived from a patient homozygous for the mutant TDP1 gene encoding the activity reduced H493R-TDP1 variant (H493R-LCL) and LCL cells expressing the wt-TDP1 enzyme (wt-LCL). As shown in Fig. 4A close to no signal was detected from the H493R-LCL extract compared to the wt-LCL extract. Hence, we concluded that the signal generated using the TDP1-biosensor in cellular material was specific to TDP1 activity. This is to the best of our knowledge the first TDP1biosensor tested to be specific on a cellular background.

To address whether the TDP1-biosensor also enabled quantitative detection of variations in the TDP1 activity levels in human cells, human embryonic kidney (HEK293T) cells with varying TDP1 expression levels were prepared. Cells with up-regulated TDP1 expression was achieved by transfection of the cells with an expression plasmid having the wt-TDP1 gene under the control of a strong constitutive promoter leading to an approximately 2 fold overexpression of TDP1 protein compared to mock transfected cells (Fig. 4B). TDP1 down-regulation was achieved by transfection of the HEK293T cells with TDP1-specific siRNA resulting in an approximately 2 fold reduction of the TDP1 protein level compared to mock transfected cells (Fig. 4C).

The TDP1 activity levels in extracts from cells with up- or down-regulated TDP1 expression, quantified from western blots were examined and compared to that of the mock-transfected cells. As illustrated in Fig. 4B the approximate 2 fold up-regulation of TDP1 amount corresponded to a 2.4 fold increase in TDP1 activity as measured by our assay. Analysis of extracts from TDP1siRNA treated cells showed a decrease in TDP1 activity of 1.7 fold compared to the mock-siRNA treated cells (Fig. 4C). Thus, the TDP1-biosensor is capable of not only detecting the presence of TDP1 activity but also of quantifying the level of TDP1 activity in human cells.

\section{Conclusion}

Although it has been shown previously that TDP1 is capable of removing many different 3 'lesions from DNA it has to the best of 
our knowledge never been tested whether TDP1 can remove a quencher from DNA. We show that TDP1 is capable of removing a number of quenchers, enabling detection of TDP1 with an optical quencher-fluorophore-based biosensor. The TDP1-biosensor here presented allowed specific and quantitative real-time measurements of TDP1-activity not only of purified TDP1 but also in crude cellular extracts.

The TDP1-biosensor is based on a very simple design and has several benefits: Firstly, it consists of DNA and a quencherfluorophore pair allowing enzyme activity to be measured as an increase in fluorescence using any standard real-time PCR machine, fluorimeter or other device capable of measuring fluorescence over time. Secondly, it is extremely fast and easy to use, requires no radioactive labeling or gel casting, and results may be obtained within 15-30 min. Thirdly, it is specific even in complex cellular material where it is capable of detecting both up- and down-regulation of TDP1 activity. Finally, it is well suited for screening and analysis of TDP1-inhibitors since it may be used in high throughput systems and allows kinetic analysis.
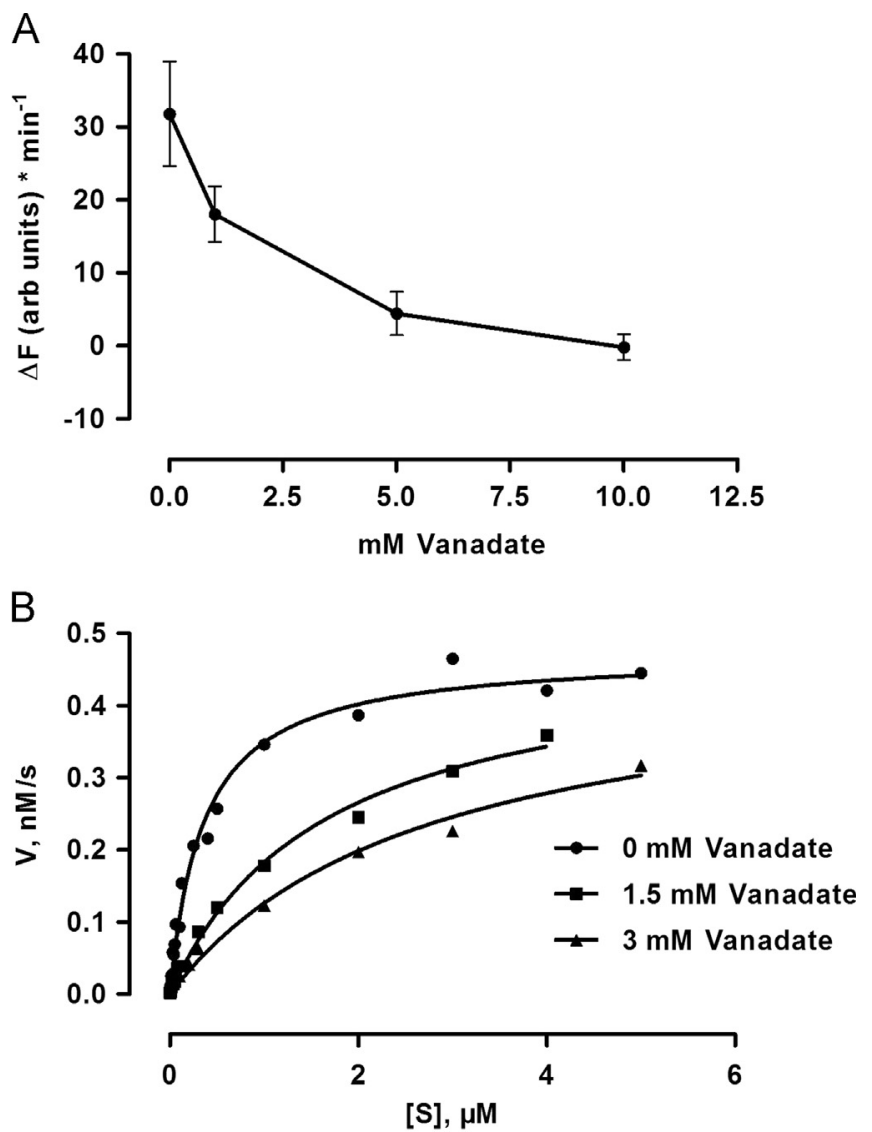

Fig. 3. Using the TDP1-biosensor for analyzing TDP1 inhibition. (A) The TDP1biosensor was incubated with purified wt-TDP1 $(2.4 \mathrm{nM})$ in presence of $0 \mathrm{mM}$ $1 \mathrm{mM}, 5 \mathrm{mM}$, or $10 \mathrm{mM}$ vanadate and the increase in fluorescence over time was measured while the reaction was still in the initial linear phase. All reactions were performed in triplicates with a final concentration of biosensor of $1 \mu \mathrm{M}$ in $25 \mu \mathrm{L}$ reaction. (B) To examine the mechanism of vanadate inhibition, increasing concentration of the TDP1-biosensor was incubated with a fixed final concentration of purified wt-TDP1 $(2.4 \mathrm{nM})$ in presence of increasing vanadate concentration and the increase in fluorescence over time was measured. The data from triplicate experiments are shown in the graph and was used to calculate $V_{\max }$ of the reaction in presence of $0 \mathrm{mM}, 1.5 \mathrm{mM}$, and $3 \mathrm{mM}$ vanadate $\left(0.47 \mathrm{nM} \mathrm{s}^{-1} ; 0.48 \mathrm{nM} \mathrm{s}^{-1}\right.$; and $0.47 \mathrm{nM} \mathrm{s}^{-1}$, respectively).
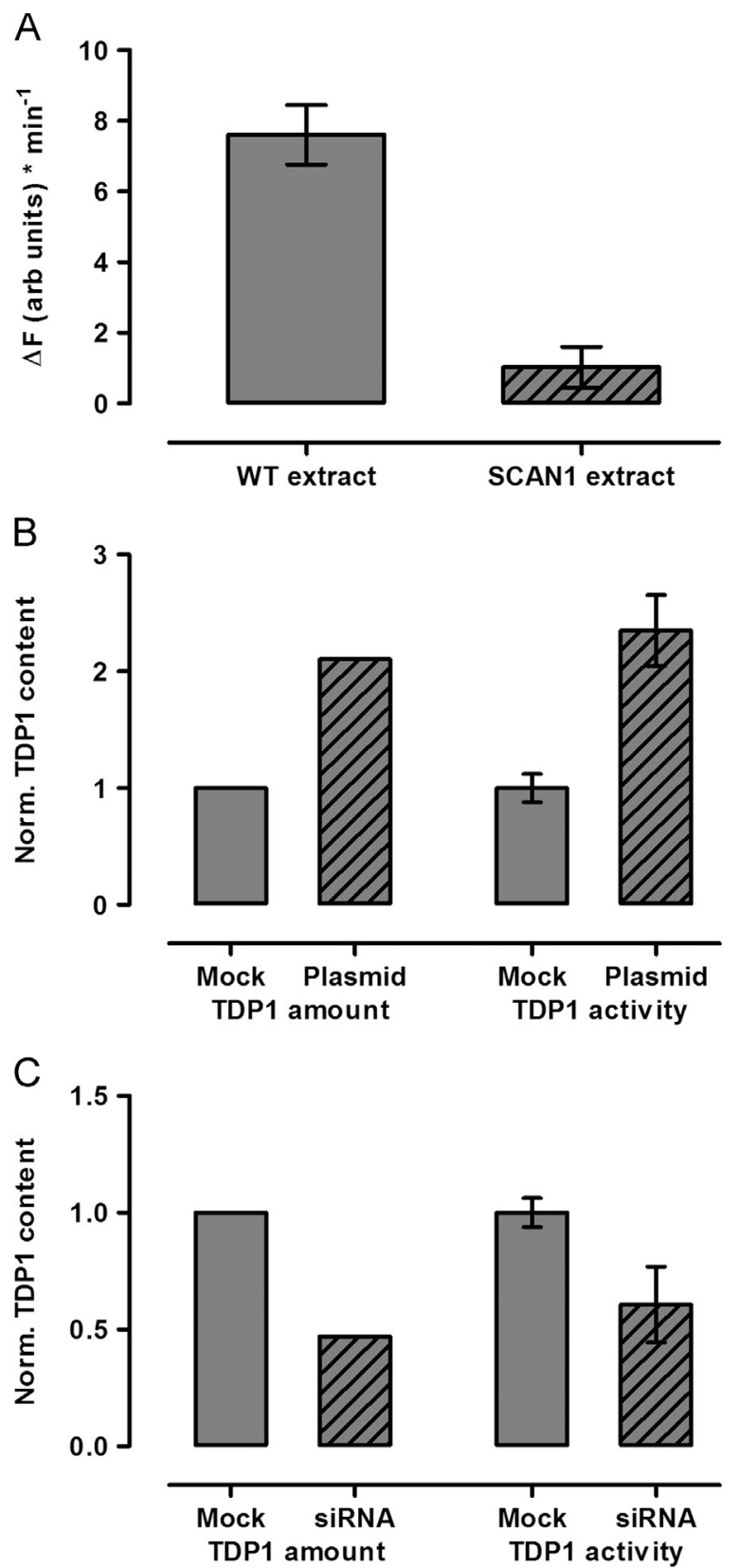

Fig. 4. Specific detection of TDP1 activity in complex cellular material. (A) The TDP1-biosensor, with a final concentration of $1 \mu \mathrm{M}$ per $25 \mu \mathrm{L}$ reaction, was incubated with nuclear extract from cell lines endogenously expressing either the wt- or H493R-TDP1 and the increase in fluorescence over time was measured. All reactions were performed in triplicates and the collected data were used to calculate the slope of the reactions in the linear phase corresponding to the enzymatic activity of TDP1. (B) TDP1 quantification in nuclear extract from HEK$293 \mathrm{~T}$ cells transiently transfected with a plasmid resulting in constitutive expression of the wt-TDP1 enzyme. Left column shows the amount of TDP1 protein following plasmid transfection quantified from a western blot. Right column shows the corresponding change in TDP1 activity quantified using the TDP1-biosensor in a final concentration of $1 \mu \mathrm{M}$ per $25 \mu \mathrm{L}$ reaction. The reactions were performed in triplicates, and the collected data were used to calculate the slope of the reaction in the linear phase corresponding to the enzymatic activity of TDP1. (C) TDP1 quantification in nuclear extract from HEK-293 T cells transfected with TDP1 specific siRNA. Left column shows the amount of TDP1 protein following transfection with TDP1 specific siRNA knock-down quantified from a western blot. Right column shows the corresponding change in TDP1 activity quantified using the TDP1-biosensor in a final concentration of $1 \mu \mathrm{M}$ per $25 \mu \mathrm{L}$ reaction. The reactions were performed in triplicates, and the collected data were used to calculate the slope of the reaction in the linear phase corresponding to the enzymatic activity of TDP1. 


\section{Acknowledgments}

This work was supported by grants from the Aase og Ejnar Danielsens Foundation, the Købmand Svend Hansen og hustru Ina Hansens Foundation, the Familien Hede Nielsens Foundation, the Marie \& M. B. Richters Foundation, the Fabrikant Einar Willumsens Mindelegat, the Kong Christian Den Tiendes Fond, the Lykfeldts legat, the Fhv. Dir. Leo Nielsen og Hustru Karen Margrethe Nielsens Legat for Lægevidenskabelig Grundforskning, the Familien Erichsens mindefond, and the Italian association for cancer research (AIRC) project N. 10121. We also thank Noriko Hansen for technical assistance during this project.

\section{References}

Andersen, F.F., Stougaard, M., Jorgensen, H.L., Bendsen, S., Juul, S., Hald, K., Andersen, A.H., Koch, J., Knudsen, B.R., 2009. ACS Nano 3 (12), 4043-4054.

Antony, S., Marchand, C., Stephen, A.G., Thibaut, L., Agama, K.K., Fisher, R.J., Pommier, Y., 2007. Nucleic Acids Research 35 (13), 4474-4484.

Barthelmes, H.U., Habermeyer, M., Christensen, M.O., Mielke, C., Interthal, H., Pouliot, J.J., Boege, F., Marko, D., 2004. Journal of Biological Chemistry 279 (53), 55618-55625.

Belle, D.J., Singh, H., 2008. American Family Physician 77 (11), 1553-1560.

Beretta, G.L., Cossa, G., Gatti, L., Zunino, F., Perego, P., 2010. Current Medicinal Chemistry 17 (15), 1500-1508.

Cheng, T.J., Rey, P.G., Poon, T., Kan, C.C., 2002. European Journal of Biochemistry/ FEBS 269 (15), 3697-3704.

Dai, N., Kool, E.T., 2011. Chemical Society Reviews 40 (12), 5756-5770.

Das, B.B., Dexheimer, T.S., Maddali, K., Pommier, Y., 2010. Proceedings of the National Academy of Sciences of the United States of America 107 (46), 19790-19795.

Davies, D.R., Interthal, H., Champoux, J.J., Hol, W.G., 2002. Journal of Molecular Biology 324 (5), 917-932.

Dexheimer, T.S., Antony, S., Marchand, C., Pommier, Y., 2008. Anti-cancer Agents in Medicinal Chemistry 8 (4), 381-389.

Dexheimer, T.S., Stephen, A.G., Fivash, M.J., Fisher, R.J., Pommier, Y., 2010. Nucleic Acids Research 38 (7), 2444-2452.

El-Khamisy, S.F., Saifi, G.M., Weinfeld, M., Johansson, F., Helleday, T., Lupski, J.R. Caldecott, K.W., 2005. Nature 434 (7029), 108-113.

Graham, F.L., van der Eb, A.J., 1973. Virology 54 (2), 536-539.

Grosjean, F., Bertschinger, M., Hacker, D.L., Wurm, F.M., 2006. Biotechnology Letters 28 (22), 1827-1833.
Hawkins, A.J., Subler, M.A., Akopiants, K., Wiley, J.L., Taylor, S.M., Rice, A.C., Windle, J.J., Valerie, K., Povirk, L.F., 2009. DNA Repair 8 (5), 654-663.

Hirano, R., Interthal, H., Huang, C., Nakamura, T., Deguchi, K., Choi, K., Bhattacharjee, M.B., Arimura, K., Umehara, F., Izumo, S., Northrop, J.L., Salih, M.A., Inoue, K., Armstrong, D.L., Champoux, J.J., Takashima, H., Boerkoel, C.F., 2007. EMBO Journal 26 (22), 4732-4743.

Hsiang, Y.H., Hertzberg, R., Hecht, S., Liu, L.F., 1985. Journal of Biological Chemistry 260 (27), 14873-14878.

Inamdar, K.V., Pouliot, J.J., Zhou, T., Lees-Miller, S.P., Rasouli-Nia, A., Povirk, L.F., 2002. Journal of Biological Chemistry 277 (30), 27162-27168.

Interthal, H., Chen, H.J., Champoux, J.J., 2005a. Journal of Biological Chemistry 280 (43), 36518-36528.

Interthal, H., Chen, H.J., Kehl-Fie, T.E., Zotzmann, J., Leppard, J.B., Champoux, J.J., 2005b. EMBO Journal 24 (12), 2224-2233.

Interthal, H., Pouliot, J.J., Champoux, J.J., 2001. Proceedings of the National Academy of Sciences of the United States of America 98 (21), 12009-12014.

Juul, S., Ho, Y.P., Koch, J., Andersen, F.F., Stougaard, M., Leong, K.W., Knudsen, B.R., 2011. ACS Nano. 5(10), 8305-8310.

Liu, C., Zhou, S., Begum, S., Sidransky, D., Westra, W.H., Brock, M., Califano, J.A., 2007. Lung Cancer 55 (3), 303-311.

Perego, P., Cossa, G., Tinelli, S., Corna, E., Carenini, N., Gatti, L., De Cesare, M., Ciusani, E., Zunino, F., Luison, E., Canevari, S., Zaffaroni, N., Beretta, G.L., 2012. Biochemical Pharmacology 83 (1), 27-36.

Pourquier, P., Pilon, A.A., Kohlhagen, G., Mazumder, A., Sharma, A., Pommier, Y., 1997a. Journal of Biological Chemistry 272 (42), 26441-26447.

Pourquier, P., Ueng, L.M., Kohlhagen, G., Mazumder, A., Gupta, M., Kohn, K.W., Pommier, Y., 1997b. Journal of Biological Chemistry 272 (12), 7792-7796.

Raymond, A.C., Staker, B.L., Burgin Jr., A.B., 2005. Journal of Biological Chemistry 280 (23), 22029-22035.

Rideout, M.C., Raymond, A.C., Burgin Jr., A.B., 2004. Nucleic Acids Research 32 (15), 4657-4664.

Stougaard, M., Juul, S., Andersen, F.F., Knudsen, B.R., 2011. Integrative Biology: Quantitative Biosciences From Nano to Macro 3 (10), 982-992.

Stougaard, M., Lohmann, J.S., Mancino, A., Celik, S., Andersen, F.F., Koch, J., Knudsen, B.R., 2009. ACS Nano 3 (1), 223-233.

Takashima, H., Boerkoel, C.F., John, J., Saifi, G.M., Salih, M.A., Armstrong, D., Mao, Y., Quiocho, F.A., Roa, B.B., Nakagawa, M., Stockton, D.W., Lupski, J.R., 2002. Nature Genetics 32 (2), 267-272.

Wigler, M., Pellicer, A., Silverstein, S., Axel, R., 1978. Cell 14 (3), 725-731.

Yang, S.W., Burgin Jr., A.B., Huizenga, B.N., Robertson, C.A., Yao, K.C., Nash, H.A., 1996. Proceedings of the National Academy of Sciences of the United States of America 93 (21), 11534-11539.

Yu, J., Shannon, W.D., Watson, M.A., McLeod, H.L., 2005. Clinical Cancer Research 11 (5), 2053-2062.

Zhou, T., Lee, J.W., Tatavarthi, H., Lupski, J.R., Valerie, K., Povirk, L.F., 2005. Nucleic Acids Research 33 (1), 289-297. 